\title{
Nós e os outros: autonomia e recepção na autotradução de João Ubaldo Ribeiro
}

\author{
Sarah C. Lucena ${ }^{1}$
}

\begin{abstract}
Resumo: No campo dos Estudos de Tradução, o fenômeno da autotradução - termo que caracteriza traduções realizadas pelo próprio autor do texto original - é um tema ainda pouco explorado em comparação com as pesquisas em tradução, necessitando ser visitado pela crítica uma vez que o sistema literário brasileiro conta com um caso exemplar. Assim, na primeira parte deste artigo discutiremos as estratégias autotradutórias em Viva o Povo Brasileiro, vertido do português para o inglês pelo seu autor, João Ubaldo Ribeiro, sob o novo título de An Invincible Memory. Em seguida, analisaremos como a crítica anglófona recebeu o projeto de Ribeiro em comparação com seu romance original para refletir sobre as condições de existência da literatura brasileira no exterior, cuja autonomia se vê limitada quando traduzida para um contexto mercadológico hegemônico como o de língua inglesa.
\end{abstract}

Palavras-chave: Tradução literária, Autotradução, Recepção, Estratégias Tradutórias, João Ubaldo Ribeiro.

No ano de 1984, quando dos primeiros vislumbres do fim de uma ditadura militar que se prolongava no Brasil desde a década de 1960, o escritor baiano João Ubaldo Ribeiro (1941-2014) publica seu premiado romance Viva o Povo Brasileiro (1984), cuja robustez conta uma história panorâmica do Brasil desde o período pré-colonial até a década de 1970, num enredo que se vê contemporâneo à própria construção do livro. $\mathrm{Na}$ cronologia da obra, que faz uso do romance

1 Doutora em Línguas Românicas pela University of Georgia, com especialização em Literatura Brasileira Contemporânea. Professora do Departamento de Espanhol e Português na Georgetown University. E-mail: sarah.lucena@ georgetown.edu

Gláuks: Revista de Letras e Artes - jul/dez 2020 - v. 20, n. 2 


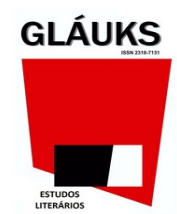

histórico para desenvolver uma narrativa de fundação do povo brasileiro, a prosa se inicia no século XVII, na Bahia, e vai até o ano de 1975, em São Paulo. Ainda que indique a sua temporalidade nas páginas que acompanham o leitor, o romance tem uma marcação temporal não linear, presente em outros romances históricos como Valentia (2012), de Deborah Goldemberg, que repete a estrutura de Ribeiro ao compor uma narrativa erigida sob um tempo não convencional, de uma cronologia movediça ${ }^{2}$. Em Viva o Povo Brasileiro, Ribeiro alterna épocas e países diferentes ao longo dos seus vinte capítulos - por exemplo, um momento que se passa em 1826 é precedido de outro que se passa em 1647, que antecede um tempo seguinte que volta/vai para 1822. Trata-se de um mosaico temporal em que, por meio do intercalar dos anos e séculos, permite ao leitor construir associações entre eventos e personagens até notar que o romance costura uma linhagem genealógica da história da nação brasileira ${ }^{3}$.

Cinco anos depois, em 1989, Ribeiro publica nos Estados Unidos An Invincible Memory (1989), que se trata, na verdade, de uma autotradução de Viva o Povo Brasileiro. Concordando com André Lefevere (2007, p. 11), teórico dos estudos tradutórios que considera a tradução - seja a realizada por um sujeito distinto do autor, seja o caso da autotradução - uma reescritura, e, como tal, "manipula a literatura para que ela funcione dentro de uma sociedade determinada e de uma forma determinada", este artigo faz uma comparação analítica entre as duas versões do romance de Ribeiro a partir da seguinte pergunta: como a escrita do nós - Viva o Povo Brasileiro - se coloca na escrita para o outro - An Invincible Memory? A partir daí, pretendemos refletir sobre as condições de existência da literatura brasileira no exterior, especificamente no contexto da língua inglesa, a partir do caso de João Ubaldo Ribeiro, concluindo que a autonomia do romance brasileiro é limitada quando traduzido para um meio hegemônico como o anglófono, que demanda estratégias de adequação do projeto original orientadas pelo contexto mercadológico para onde o romance é vertido.

2 A respeito do tempo cindido no romance histórico, ver Lucena (2018).

3 Temática muito similar pode ser encontrada em A Mãe da Mãe de Sua Mãe e Suas Filhas (2002), de Maria José Silveira, mas desta vez a linhagem genealógica da nação brasileira é costurada pelas mulheres.

Gláuks: Revista de Letras e Artes - jul/dez, 2020 - v. 20, n. 2 
Segundo dados apresentados por Cimara Valim de Melo (2017) em pesquisa sobre a representação da literatura brasileira no mundo anglófono, somente 3\% dos livros publicados nos Estados Unidos são traduções e, destes, menos de 1\% integram poesia e ficção estrangeira. De forma complementar, Elizabeth Lowe (2013) mostra que, enquanto anualmente os Estados Unidos publicam somente estes 3\%, países como a França e o Brasil apresentam, respectivamente, $27 \%$ e $40 \%$ de obras de ficção traduzidas a cada ano. Por sua vez, Heloísa Gonçalves Barbosa (1994) aponta para a dificuldade de fazer transitar a literatura estrangeira no mundo anglófono, especificamente entre os Estados Unidos e o Reino Unido. Barbosa mostra que os livros em português que chegam aos Estados Unidos não cruzam o Atlântico com facilidade, o que causa um impacto negativo à recepção da literatura brasileira no exterior. Tais fatos combinados - baixo número de traduções e dificuldade de circulação - apontam para um primeiro obstáculo que limita a autonomia e a presença da literatura brasileira em terra estrangeira. Especificamente sobre a crítica da autotradução de Ribeiro, pesquisas já vinham apontando para diferenças entre as duas versões como sendo de orientação mercadológica. Maria Alice G. Antunes (2009a) informa que a autotradução de Viva o Povo Brasileiro começou no mesmo ano de sua publicação, em 1984, e durou dois anos de trabalho até ser publicada nos Estados Unidos em 1989. Segundo a autora, a motivação primordial para que Ribeiro realizasse sua autotradução foi a insistência do agente literário do escritor. O agente, por sua vez, argumentava que nenhum tradutor norte-americano conseguiria compreender "a complexidade do romance", bem como todos os tipos de "sublínguas" nele presentes (ANTUNES, 2009a, p. 166).

Além disso, Antunes (2009b) lembra também que não se pode deixar de lado o papel que a tradução tem de possibilitar um acesso e alcance da obra por um número maior e mais diverso de leitores não apenas norte-americanos, mas leitores de língua inglesa. O empenho do agente em convencer Ribeiro revela, assim, um interesse mercadológico fruto do sucesso que Viva o Povo Brasileiro obteve no Brasil, mas também da presença internacional que o próprio

Gláuks: Revista de Letras e Artes - jul/dez 2020 - v. 20, n. 2 


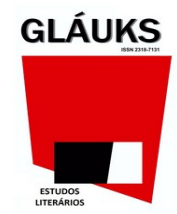

Ribeiro tem ${ }^{4}$. Antunes (2010) segue mostrando que Ribeiro aposta na autotradução como meio de alcançar maior visibilidade e existência literária no exterior, o que possivelmente explica, por exemplo, que o romancista tenha eliminado a "linguagem regional" essencial à sua escrita com o intuito de dar um "ar traduzido" ao seu romance em inglês (ANTUNES, 2009b, p. 71). O romance autotraduzido, no entanto, não se consagrou internacionalmente, embora tenha trazido ao escritor ainda mais prestígio no Brasil (ANTUNES, 2009a, p. 163).

Breno Fernandes Pereira (2016, p. 162), ao promover, em conjunto com a autotradução, uma análise estética das diferentes capas que o romance ganha nas edições inglesa e brasileira, conclui que "a resistência mnemônica dos inferiorizados" que informa Viva o Povo Brasileiro é abandonada na versão em inglês pelo estereótipo do Brasil como um país "exoticamente primitivo". No entanto, contrário ao argumento de que os livros traduzidos são realizados a partir das estratégicas dicotômicas de domesticação/estrangeirização sustentadas por Lawrence Venuti (2008), Pereira lê as obras brasileiras traduzidas para o inglês à luz do hibridismo de Homi Bhabha (1998). Em outras palavras, o encontro entre culturas por meio da tradução resulta no hibridismo, que "não é sinônimo nem garantidor de equilíbrio, é tão-somente o meio pelo qual as culturas estabelecem relações entre si” (PEREIRA, 2016, p. 172). Portanto, Pereira não percebe a readequação linguística que elimina, entre outros aspectos, o linguajar regional de Viva o Povo Brasileiro como um sintoma de perda, mas sim como o resultado do contato entre duas culturas que resulta num produto híbrido.

Em Lucena (2013), consideramos cada um dos dois romances um caso de reescritura textual dupla: num primeiro momento, Ribeiro reescreve em português eventos da história brasileira, para o público brasileiro, acrescentando-lhe ângulos, vozes e geografias tradicionalmente marginalizados pela historiografia oficial. Em seguida, reescreve-os outra vez, quando realiza a autotradução para o inglês, sem deixar de se orientar pelo seu novo leitor-

4 A editora Companhia das Letras, que publica boa parte dos títulos de Ribeiro, afirma que Viva o Povo Brasileiro já vendeu mais de 120 mil exemplares e que o escritor foi traduzido para 16 países.

Gláuks: Revista de Letras e Artes - jul/dez 2020 - v. 20, n. 2 
modelo para resolver como serão acrescentados estes ângulos, vozes e geografias que, por padrão, não fazem parte do imaginário deste novo leitor. Assim, percebendo cada texto como produções discursivas orientadas por recepções diversas, cotejaremos, a seguir, trechos das duas obras para apontar reflexões sobre os caminhos pelos quais percorre a literatura brasileira no exterior.

\section{Ver e Ser Visto}

Em Translation and Cultural Hegemony, Richard Jacquemond (1992) esboça as características de uma teoria de tradução baseada tanto no contexto cultural em que as obras se encontram quanto à luz da hegemonia e dependência entre as culturas em questão. Para o investigador, haveria, a partir desse raciocínio, dois tipos de tradução: uma de feição colonial e uma de feição pós-colonial, tipos que devem ser compreendidos sob parâmetros literários, uma vez que uma simples classificação temporal não seria suficiente para caracterizar dois tipos de texto que, na verdade, coexistem no tempo (JACQUEMOND, 1992, p. 155).

Com base no estudo de Jacquemond, foi mostrado em Lucena (2013, p. 91) que a tradução colonial aconteceria dentro de dois paradigmas: a) na tradução de sentido cultura hegemônica para periférica, o tradutor aparece como um mediador servil ("servile mediator") que irá integrar o outro a si sem questionar essa dominação; e b) no caso do sentido periféricohegemônico, o tradutor aparece como o mediador autorizado ("authoritative mediator") para ultrapassar seus próprios limites e ao mesmo tempo trabalhar para se adaptar (JACQUEMOND, 1992, p. 155).

Gláuks: Revista de Letras e Artes - jul/dez 2020 - v. 20, n. 2 


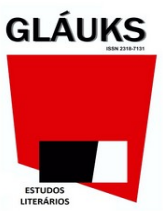

Em relação à tradução pós-colonial, Jacquemond (1992, p. 155) afirma que o paradigma acima pode ser questionado porque o caráter pós-colonial é de resistência a novos tipos de colonialismos, o que implica uma postura tradutória que problematiza estratégias tanto de naturalização/domesticação ou estrangeirização do texto traduzido quanto da invisibilidade do tradutor.

Em relação à tradução para o inglês de Viva o Povo Brasileiro, é necessário considerar o que Venuti (2006, p. 174) ressalta sobre os trabalhos traduzidos: a sua responsabilidade, pelo poder que tem "de construir representações de culturas estrangeiras". O texto traduzido representa o potencial de construir visões do outro e instituir mudanças na representação doméstica desse outro:

\footnotetext{
Na medida em que a tradução constrói uma representação doméstica para um texto e uma cultura estrangeiros, ela ao mesmo tempo constrói um sujeito doméstico, uma posição de inteligibilidade que também é uma posição ideológica, delineada pelos códigos e cânones, interesses e pautas de certos grupos sociais domésticos. (VENUTI, 2006, p. 175)
}

A mencionada responsabilidade da tradução se refletiria na consciência de que, em todo texto, está presente uma "inclinação ideológica" a qual "está inscrita em escolhas discursivas específicas que funcionam tanto para criar uma identidade subordinada como para fazê-la parecer natural ou óbvia" (VENUTI, 2002, p. 13). Ao mesmo tempo que a tradução pode formar e manter representações homogeneizadas pelo tempo, ela também "cria possibilidades de mudança, inovação e resistência cultural em qualquer momento histórico" (VENUTI, 2006, p. 176). Nesse sentido, a tradução se transforma em um local em potencial de questionamento.

Como mostrado em Lucena (2013), em Escândalos da Tradução, Venuti (2002) concentra parte de sua discussão na ação de interferência que as traduções de literaturas

\section{Gláuks: Revista de Letras e Artes - jul/dez, 2020 - v. 20, n. 2}




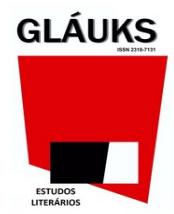

consideradas minoritárias podem exercer em relação ao inglês, que ele chama de dialeto-padrão global. Venuti (2002, p. 27) afirma que textos estrangeiros "estilisticamente inovadores" convidam o tradutor para inglês a criar "socioletos marcados por diversos dialetos, registros e estilos" que questionem a suposta unidade do inglês, "promovendo inovação cultural, assim como entendimento da diferença cultural ao proliferar as variáveis dentro da língua inglesa”. Nos trechos compilados a seguir, veremos que a tradução enquanto espaço de problematizações e questionamentos será sempre um local virtual, como uma potência, que se concretiza a depender da atuação do tradutor. Para Lefevere (2007, p. 143), essa atuação se faz no modo como o tradutor atua diante da relação entre o universo de discurso expresso no original e o universo de discurso da sociedade. O texto traduzido pretende fundar um espaço seu na cultura para onde se dirige, havendo, portanto, uma busca por facilitar a sua recepção (LEFEVERE, 2007, p. 150). Com isso em mente, façamos uma observação da primeira palavra que abre o romance de Ribeiro em português: contudo.

Contudo, nunca foi bem estabelecida a primeira encarnação do alferes José Francisco Brandão Galvão [...] (RIBEIRO, 2009, p. 9)

Nobody ever established for sure the first incarnation of Warrant Officer José Francisco Brandão Galvão [...] (RIBEIRO, 1989, p. 1)

A conjunção contudo, omitida na versão em inglês, leva a supor que a perspectiva adversativa que situa Viva o Povo Brasileiro não é utilizada da mesma maneira em An Invincible Memory. Eneida Leal Cunha (2007, p. 8) mostra que a conjunção que abre o romance serve como um aviso para se ter sempre em mente que se está lendo um texto que coexiste com um outro precedente, com o qual "dialoga, contrasta, suplementa", sendo esse outro precedente o próprio cânone literário nacional.

Gláuks: Revista de Letras e Artes - jul/dez 2020 - v. 20, n. 2 


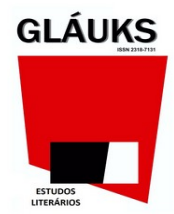

Outro elemento que aponta para os diferentes modos de reescritura de Viva o Povo Brasileiro em inglês diz respeito ao título. Se, em português, Viva o Povo Brasileiro pode tanto ser lido como uma exclamação de aplauso, ainda pode ser compreendido como um sentido expresso pelo verbo viver, que ordena ou sugere que o povo brasileiro prossiga e perdure. Para Rita Olivieri-Godet (2008, p. 49), o título em português "guarda a ambiguidade dos discursos sobre o povo brasileiro que a narrativa revisitará". Escolha distinta foi feita para a versão anglófona, An Invincible Memory, literalmente Uma Memória Invencível. Ao mesmo tempo indica se tratar de um romance que tematiza o passado, através da permanência da memória no tempo, como também "alude mais claramente à noção de conflito, a partir da qual o romance se constrói” (OLIVIERI-GODET, 2009, p. 50). Pode-se interpretar, então, que An Invincible Memory se coloca narrativamente de forma mais direta, utilizando menos ambiguidades ou outros recursos como metáforas ou elipses, que estão presentes no texto de Viva o Povo Brasileiro.

Ao longo de suas mais de quinhentas páginas, o romance traz discursos de personagens combatentes e revolucionários que retomam a saudação exclamativa do título em português como meio de afirmação. Em inglês, o que se vê é que a conexão com o título não é realizada diretamente, como também se nota uma voz narrativa distanciada da história do povo, o que não acontece em português:

Budião enfiou a cabeça no chapéu, que estava pendurado no pescoço, levantou a mão. - Viva nós! - disse sorrindo. nosso)

— Viva nós! — respondeu Zé Pinto muito sério. (RIBEIRO, 2009, p. 367, grifo

Budião put on the hat that had been hanging from his neck and raised his hand.

"Long live the people!" he said, smiling.

"Long live the people!" Zé Pinto answered, very serious. (RIBEIRO, 1989, p. 235, grifo nosso)

Gláuks: Revista de Letras e Artes - jul/dez 2020 - v. 20, n. 2 


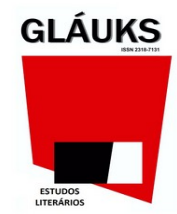

A "desinclusão" pela não utilização do pronome pessoal nós, que se repete em outros trechos do romance, indica menos parcialidade em relação à história da uma nação, sugerindo que a narrativa anglófona tenta construir uma maior identificação com o leitor que também não possui laços históricos de identidade e identificação com a história do povo brasileiro. Há, em português, uma vinculação clara seja à ideia de nação brasileira, seja aos eventos do território nacional: "Que acha de todas as lutas do Brasil, que opinião tem sobre a nossa Independência [...]?” (RIBEIRO, 2009, p. 14, grifo nosso). Já em inglês, continua a ser notado o distanciamento pela ausência do pronome possessivo nossa: "What does he think about Brazil's struggle, what is his opinion about Independence [...]?” (RIBEIRO, 1989, p. 4).

Se na obra anglófona a intenção primeira era se fazer fluente para assegurar a boa compreensão do texto, é provável que a obra traga um caráter assimilativo inscrito na busca dessa fluência (VENUTI, 2002, p. 29). Essa estratégia tradutória resultará em possíveis maneiras de receber e perceber An Invincible Memory que podem se mostrar desvinculadas de seu sentido histórico, "excluindo valores, debates e conflitos que não estejam a serviço de agendas domésticas", aponta Venuti (2002, p. 130).

Outra estratégia comum presente na autotradução de Ribeiro é a manutenção de palavras em português que são semelhantes ou iguais ao espanhol: "nhô mestre feitor Almério" (RIBEIRO, 2009, p. 214, grifo nosso) se converte em "senhor master foreman Almério" (RIBEIRO, 1989, p. 135, grifo do autor). O mesmo acontece em "Muito bem, minha gente, chegou São João, quem não for compadre que se acompadre!” (RIBEIRO, 2009, p. 405, grifo nosso), que aparece como “All right, folks, Saint John's arrived. Those who are not yet compadres better see to it right now!” (RIBEIRO, 1989, p. 259, grifo do autor). Uma vez que um país de língua inglesa a exemplo dos Estados Unidos historicamente está em contato com o espanhol mais do que com o português, o autotradutor pode ter se valido dessa aproximação para criar outra chance de aceitação maior por parte do mundo anglófono.

Gláuks: Revista de Letras e Artes - jul/dez 2020 -v. 20, n. 2 


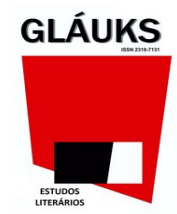

Como notado em Lucena (2013), ao mesmo tempo que o escritor busca promover uma aproximação com o leitor pelas semelhanças entre o português e o espanhol, também termina por fortalecer a associação da língua espanhola com povos desfavorecidos social e economicamente, já que emprega esses termos não traduzidos na fala de personagens historicamente desautorizados, como negros, escravos e ex-escravos ou empregados. Camila Werner (2009) apresenta outro dado revelado pelo estudo da tradução de ficção escrita em línguas consideradas periféricas em relação ao inglês: não é incomum que livros escritos em português utilizem o espanhol como uma "língua de conexão" para se aproximar do mercado anglófono:

O caminho que leva um trabalho escrito em uma língua periférica, o português por exemplo, a atingir o centro do sistema e consequentemente a se espalhar pelo resto do sistema não é direto. Pode-se dizer que há uma 'escadaria' que leva ao centro do sistema. No caso das línguas periféricas, o primeiro degrau seria a tradução para uma 'língua de conexão' que pertença ao mesmo grupo lingüístico e/ou esteja próxima do ponto de vista cultural e histórico. No caso do português, não há dúvida de que o espanhol desempenha esse papel. (WERNER, 2009, p. 6)

A respeito de estratégias textuais híbridas em textos periféricos traduzidos, Venuti aponta:

As situações coloniais e pós-coloniais complicam essa distinção entre mesmidade e diferença. Nesses casos, a tradução move-se entre diferenças múltiplas, desigualdades não somente culturais, mas também econômicas e políticas, de modo que formam identidades domésticas que participam das culturas hegemônicas enquanto submetem aquelas culturas a uma heterogeneidade nativa. (VENUTI, 2002, p. 353)

É uma estratégia de inscrição do outro que pode refletir uma intenção de Ribeiro de fornecer um texto fluente pela pasteurização da linguagem e pela escolha de palavras estrangeiras

Gláuks: Revista de Letras e Artes - jul/dez 2020 - v. 20, n. 2 


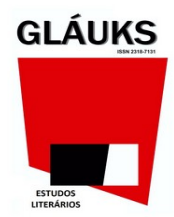

acessíveis para o leitor (a mesmidade). Ao mesmo tempo, mantém a presença de componentes híbridos (a diferença) para marcar que se trata de um texto estrangeiro, o que Antunes (2009b, p. 69) entende como uma maneira de dar "visibilidade ao trabalho do tradutor e à própria tradução". Patricia López (2006, p. 54), estudiosa da autotradução de Fernando Pessoa, afirma que pesquisas conduzidas pelo grupo de estudos Autotrad, da Universidade de Barcelona, demonstram haver um padrão de escrita em que, no original, "o autor concentra-se na criação do universo de ficção" e, quando autotraduz, está concentrado "no receptor de uma determinada cultura". Em cossonância com a conclusão de López, João Ubaldo Ribeiro demonstra que fundamentou as alterações em An Invincible Memory no possível desconhecimento de elementos culturais contidos no original e no desejo de que o leitor apenas tivesse prazer com a leitura. Diante dessa constatação, Pereira (2017, p. 198) se pergunta que tipo de leitura seria possível se fazer de $A n$ Invincible Memory sendo a obra vista como "um ato de política internacional" brasileiro, lusófono, que tenta existir em meio a uma realidade que considera o inglês como a língua franca, com todas as implicações "logocêntricas" que tal fato pode gerar. Em outras palavras, quais seriam as implicâncias do caso de João Ubaldo Ribeiro para a presença da cultura e literatura brasileira no exterior? A seguir, teceremos algumas considerações em relação ao estatuto das obras de ficção brasileira no meio anglófono a partir do caso de Ribeiro e a sua recepção no universo da língua inglesa.

\section{Modos de Existir}

Como se poderá notar abaixo, a crítica disponível sobre o romance autotraduzido de Ribeiro para o inglês mostra dois pontos: o primeiro, o terreno de ambivalências em que se encontra a recepção de uma obra brasileira traduzida; e segundo, a institucionalização de uma percepção negativa do romance em inglês apesar de, no Brasil, ter ganhado prêmios e constar do

Gláuks: Revista de Letras e Artes - jul/dez 2020 - v. 20, n. 2 


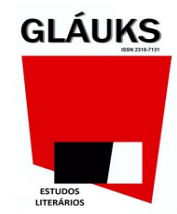

cânone da literatura nacional. Em termos de presença da literatura brasileira no exterior, $A n$ Invincible Memory não parece conseguir manter o destaque que ganha no Brasil, mas sim sublinhar os obstáculos que a nossa literatura enfrenta ao viajar para o exterior.

O professor e autor de The Babel Guide of Brazilian Fiction in English Translation (1995) David Treece afirma, em Sinister Populism (1990), que An Invincible Memory parece prometer ao leitor a construção coerente da visão da experiência histórica nacional do ponto de vista dos subalternos. O crítico britânico segue afirmando que, embora Ribeiro transmita tal e qual para o inglês o discurso da libertação nacional presente na retórica dos heróis populares do romance, falha na tradução dos registros coloquiais: "As a result, the 'ordinary' characters too often lack the sense of authenticity and humanity which might make their journey of selfdiscovery convincing" (TREECE, 1990, p. 145). Treece aponta ainda que a luta do povo pela democracia apresentada por Ribeiro permanece "convenientemente distante" da realidade do século XX brasileiro, só sendo retratada em dois capítulos do romance: "This 'invincible memory' effectively excludes an entire experience of conscious class organisation and struggle which has offered for the first time a glimpse of real liberation for the majority" (TREECE, 1990, p. 146).

Por sua vez, a escritora Mary Morris aponta, em crítica publicada pelo The New York Times em 1989, que o enredo complexo e fragmentado de An Invincible Memory se mostra confuso a menos que o leitor tenha conhecimentos de história brasileira. Morris sugere: "Given the complex format and cast of characters, a simple genealogical or chronological chart would certainly have helped the North American reader ${ }^{7 \%}$. Ainda para a autora, a narrativa não

5 Em tradução livre, "Como resultado, faltam frequentemente aos personagens 'comuns' a originalidade e humanidade que tornariam convincente a sua jornada de autodescobrimento".

6 Em tradução livre, "Esta 'memória invencivel' efetivamente exclui toda uma experiência de organização de uma consciência de classe e de luta a qual possibilitou, pela primeira vez, um gostinho de libertação para uma maioria".

7 Em tradução livre, "dado o formato complexo e a escolha dos personagens, uma simples tabela genealógica ou cronológica teria certamente ajudado o leitor norte-americano".

Gláuks: Revista de Letras e Artes - jul/dez 2020 - v. 20, n. 2 


\section{GLÁUKS}

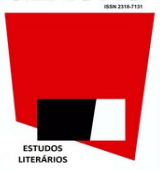

cronológica e entrecortada "never lets the reader sink very deeply into any one story", transformando An Invincible Memory em um romance de ideias contado por um estudante de história, em vez de uma história contada por um romancista.

Já Luiz Fernando Valente (1990), professor e pesquisador de literatura brasileira da Brown University, lembra que o romance foi publicado no Brasil no momento da transição do poder ditatorial militar para o civil, um período marcado pela discussão aberta sobre o passado nacional que levou a um interesse renovado pela busca das origens da identidade brasileira. Por esse motivo, Valente classifica An Invincible Memory como material de ficção brasileira disponível em inglês de melhor qualidade. Mesmo tom tem a crítica do professor da Universidade de Aveiro John Parker (1990). Embora aponte para o dado um tanto comprometedor de que a tradução de Ribeiro apresenta erros gramaticais não corrigidos pelo editor da edição norte-americana, Parker afirma que Ribeiro deveria ser parabenizado por oferecer "a highly readable version of a very readable novel"'. Curiosamente, o próprio Parker publicou uma tradução sua de um capítulo do romance para o inglês em 1987, ou seja, dois anos antes de publicada a autotradução de Ribeiro. Os textos de professores como Valente e Parker, que atuam no exterior, se transformam, portanto, em ferramentas de divulgação e circulação da cultura brasileira além de suas fronteiras e não deixam de ser um esforço coletivo de fortalecimento de nossa existência em língua inglesa.

Debatendo o estatuto da literatura brasileira no exterior a partir da experiência francófona, a professora Marie-Hélène Torres (2008, p. 34) afirma que a cultura literária brasileira, por não ser considerada central, tende a importar mais do que exportar a literatura traduzida e que, quando ela se exporta, termina por se anexar à cultura literária do outro por meio, por exemplo, de traduções que aniquilam "o modelo oral original (regionalismos, neologismos, sintaxe, agramaticalidade, ritmo, sonoridade) com o intuito de respeitar as normas

8 Em tradução livre, "não permite ao leitor mergulhar a fundo em nenhum ponto da narrativa".

9 Em tradução livre, "uma versão altamente compreensível de um romance muito compreensivel".

Gláuks: Revista de Letras e Artes - jul/dez 2020 - v. 20, n. 2 


\section{GLÁUKS}

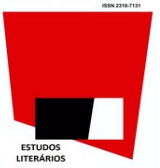

gramaticais" estrangeiras em vigor. Torres (2008, p. 34) comenta ainda que a transgressão criativa da linguagem presente no original não é um projeto necessariamente realizado na tradução, causando o que ela chama de uma metamorfose do "falar do povo" em uma língua traduzida culta. Ainda para a autora, a literatura brasileira traduzida só vai se inserir alémfronteiras "quando não reivindicar mais suas próprias normas (estéticas e literárias) nem um contexto histórico, cultural, político, literário diferenciado e específico", atitude que ela chama de “não-tradução" e ainda de "atitude antropofágica colonial” (TORRES, 2008, p. 34, 36).

Para Tatiana Fantinatti, que investigou a recepção das traduções de obras de Guimarães Rosa e Euclides da Cunha (2008, p. 54), existe uma opinião comum entre tradutores de literatura brasileira de que é "difícil a tradução de qualquer escritor brasileiro por ser a literatura brasileira dirigida a um público exclusivamente do Brasil, ao passo que escritores europeus e americanos objetivam em geral um mercado mais amplo de leitores". O raciocínio que implica em interpretar a produção nacional como limitada talvez possa ser compreendido sob uma perspectiva diversa: talvez seja o mercado internacional que esteja mais equipado para receber com menos filtros socioculturais os textos escritos originalmente em língua inglesa. A respeito especificamente da tradução de obras escritas em outras línguas para o inglês, Venuti (2002) prega a prática da "evocação do estrangeiro" como um combate à hegemonia global do inglês:

A ascendência econômica e política dos Estados Unidos reduziu as línguas e as culturas estrangeiras a minorias em relação à sua língua e cultura. $\mathrm{O}$ inglês é a língua mais traduzida em todo o mundo, mas para a qual menos se traduz, uma situação que identifica a tradução como um lugar potencial de variação. (VENUTI, 2002, p. 26)

João Ubaldo Ribeiro também escreveu uma crítica, em inglês, comentando a sua experiência com a autotradução. No texto intitulado Suffering in Translation (1989), o romancista

Gláuks: Revista de Letras e Artes - jul/dez 2020 - v. 20, n. 2 


\section{GLÁUKS}

mostra que levou mais tempo para traduzir An Invincible Memory do que para escrever Viva o Povo Brasileiro e justifica:

First, there is the cultural problem. In general, people in England and the United States know as much about Brazil as about traffic conditions in Kuala Lumpur. [...] So should I suffocate the book with hundreds of footnotes, making it longer than the New York telephone directory? [...] I hoped the reader would develop an interest in the story, and forget about having never heard of many things and events mentioned in the novel. (RIBEIRO, 1989, p. 18) ${ }^{10}$

Ribeiro revela consciência em relação à dificuldade de traduzir o livro para um leitor que não tem as mesmas referências e experiências culturais que o seu leitor original, o que em parte confirma a afirmação de Fantinatti de que o romancista brasileiro escreve pensando exclusivamente no público brasileiro, enquanto justifica a afirmação de Antunes (2009) sobre $A n$ Invincible Memory estar mais preocupado em alcançar uma fluência na leitura.

Uma das lições que se pode depreender do caso de João Ubaldo Ribeiro, que ainda em Suffering in Translation (1989) afirmou ser a tradução uma tarefa muito ingrata, é que atuou em conformidade com como as traduções dos romances brasileiros vinham sendo feitas até então, isto é, revelando que 1) ocorre uma metamorfose do falar regional do povo em uma língua traduzida culta (TORRES, 2008); 2) a tentativa de facilitar a recepção do texto pela "pouca evocação do estrangeiro", focando-se mais em promover uma leitura fluente (VENUTI, 2002); 3) e a combinação das estratégias 1 e 2 como uma tentativa de sair de um local de marginalidade e se inserir efetivamente dentro da hegemonia global que a língua inglesa representa. Existe, portanto, a constatação de que a técnica literária e narrativa do escritor brasileiro pode se ver

10 Em tradução livre, "Há, em primeiro lugar, o problema cultural. Em geral, as pessoas na Inglaterra e nos Estados Unidos conhecem o Brasil tanto quanto conhecem os problemas do trânsito em Kuala Lumpur. [...] Eu deveria então sufocar o livro com centenas de notas de rodapé, tornando-o mais longo que a lista telefônica de Nova York? Minha esperança era de que o leitor criasse um interesse pela história e se esquecesse de nunca ter ouvido falar sobre as diversas coisas e eventos mencionados no romance".

Gláuks: Revista de Letras e Artes - jul/dez 2020 - v. 20, n. 2 


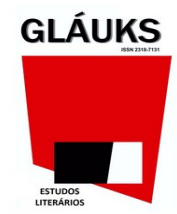

superposta pelas exigências que a tradução coloca com base na recepção para onde o texto traduzido se dirige. Por outro lado, nem toda ficção brasileira traduzida para o inglês traz como marca de sua narrativa uma linguagem considerada regional. Assim, vale a pena relativizar este ponto avaliando se os mesmos processos de adequação por que passam os romances históricos brasileiros de escrita marcadamente regionais, orais e/ou coloquiais são observados em prosas de diferentes gêneros e sem tais marcas de fala citadas.

Se considerarmos que o caso de Viva o Povo Brasileiro pode ser visto como um termômetro da experiência da literatura brasileira no exterior em fins dos anos de 1980 e inícios da década de 1990, importa avaliar também por que mudanças têm passado o percurso da literatura brasileira desde os idos do século XX até o momento atual. Heloísa G. Barbosa e Lia Wyler (2008) afirmam que, apesar de a história do Brasil se confundir com a história da tradução pelas trocas linguísticas que determinaram os contornos da nação, ainda é recente a organização dessa história tradutória brasileira. Na década de 1990, quando investigações pioneiras começaram a aparecer, os pesquisadores se deparavam com desafios logísticos que tardavam o avanço dos estudos na área, como "the paucity of public libraries in Brazil, the restricted size of their collections, and deficient cataloguing"11 (BARBOSA; WYLER, 2008, p. 341). Além disso, Barbosa e Wyler lembram que as editoras só começaram a operar no Brasil no século XIX, e a grande maioria das universidades brasileiras só são fundadas a partir do século XX. Como mostra também Barbosa (1994), no século XX os desafios encontrados para que a literatura brasileira traduzida se realizasse implicavam na dificuldade também de entender como se dava a recepção dessas obras pelos leitores estrangeiros. A maior fonte para coletar este tipo de informação estava concentrada na disponibilidade dos livros físicos em livrarias e bibliotecas. Em outras palavras, a disponibilidade de acesso que inclui e resulta em pesquisa, conhecimento, divulgação, produção,

11 Em tradução livre, "a escassez das bibliotecas públicas no Brasil, o tamanho restrito de suas coleções e a catalogação deficiente".

Gláuks: Revista de Letras e Artes - jul/dez, 2020 - v. 20, n. 2 


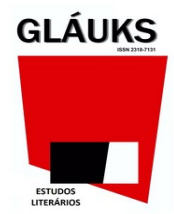

publicação da literatura brasileira no exterior dependia e depende de uma infraestrutura só recentemente estruturada no país.

É verdade, no entanto, que hoje, embora ainda seja tímido o aumento do número de romances traduzidos no século XXI, existe uma facilidade de deslocamento consideravelmente maior que une com mais rapidez os leitores aos livros (MELO, 2017, p. 27). Atualmente, os $e$ books e a própria Internet, os sistemas de empréstimos de livros entre universidades de todo o mundo, a internacionalização das editoras, feiras e festivais de literatura são verdadeiros instrumentos facilitadores do acesso à literatura brasileira e também mundial. Não se pode deixar de ressaltar também a própria solidez dos departamentos de estudos de tradução, mas também latino-americanos, de língua portuguesa e literatura brasileira no exterior, que começaram a ser fundados a partir da década de 1940 no contexto norte-americano. Estes favorecem não só o contato dos leitores estrangeiros com a literatura brasileira, mas também a formação de especialistas, pesquisadores, críticos, tradutores, professores e, claro, novos alunos, que abrem continuamente mais portas para que futuras gerações continuem a descobrir os outros mundos possíveis a partir do seu próprio.

"Do Americans hate foreign fiction?”, pergunta-se a ensaísta Anjali Enjeti. ${ }^{12}$ A resposta é complicada, afirma Enjeti, mas é importante mencionar que o mercado editorial norteamericano vem fazendo a sua parte. Em 2007, por exemplo, foi criado o Best Translated Book Award, premiação que visou movimentar a circulação de ficção estrangeira entre os consumidores de língua inglesa. Como evidencia o seu idealizador, Chad Post, uma das grandes barreiras entre o leitor anglófono e a literatura traduzida é o imaginário acerca do Outro, que se expressa no interesse (ou na falta deste) quanto à literatura estrangeira - o que explicaria, por exemplo, por que há um desejo maior de consumir traduções da ficção francesa em contraste com

12 Em tradução livre, "Os americanos odeiam ficção estrangeira?". Ver https://lithub.com/do-americans-hate-foreign-fiction/. Acesso em 9 Ago. 2020.

Gláuks: Revista de Letras e Artes - jul/dez, 2020 - v. 20, n. 2 
a brasileira. Entretanto, a cultura literária de língua inglesa não é monolítica ${ }^{13}$. Ainda que lentamente, abre-se cada vez mais ao diferente, incluindo a paisagem estrangeira como parte do seu horizonte. Com o acesso que ganhou à relação do leitor norte-americano com a literatura traduzida através da sua editora, Post resume a questão de maneira otimista: "Before people didn't want to buy translations because it wasn't the 'real' book. Now people think 'Oh, translated from Farsi, sounds pretty cool"14.

\section{Referências Bibliográficas}

ANTUNES, M. A. G. O respeito pelo original: João Ubaldo Ribeiro e a autotradução. São Paulo: Annablume, 2009a.

. Marcas no texto autotraduzido: o caso de João Ubaldo Ribeiro. Ipotesi. Juiz de Fora, v. 13, n. 1, p. 57-65, 2009b. Disponível em: <http://www.ufjf.br/revistaipotesi/>. Acesso em: 19 maio 2020.

- Autotradução: o caso do escritor brasileiro João Ubaldo Ribeiro e a versão de Sargento Getúlio / Sergeant Getúlio. Trama. Cascavel, v. 5, n. 9, p. 61-72, 2009c. Disponível em: $<$ www.abralic.org.br>. Acesso em: 19 maio 2020.

BARBOSA, H. G. The virtual image: Brazilian literature in English translation. 1994. 463p. Tese - Universidade de Warwick, Inglaterra.

BARBOSA, H. G.; WYLER, L. "Brazilian tradition." In: BAKER, M.; SALDANHA, G. Routlegde Encyclopedia of Translation Studies. Londres, Nova York: Routlegde, 2008.

13 Quem nos lembra disto é a escritora e critica literária Emily Temple. Ver https://lithub.com/what-will-happen-to-the-novelafter-this/. Acesso em: 7 Ago. 2020

14 Em tradução livre, “Antes as pessoas não queriam comprar traduções porque não eram o livro 'verdadeiro'. Agora, as pessoas pensam: 'Ah, foi traduzido do farsi, que interessante'”.

Gláuks: Revista de Letras e Artes - jul/dez 2020 - v. 20, n. 2 


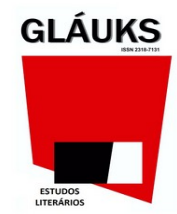

BHABHA, H. O local da cultura. Trad. de Myriam Ávila, Eliana Lourenço de Lima Reis e Gláucia Renate Gonçalves. Belo Horizonte: Editora da UFMG, 1998.

CUNHA, E. L. Viva o povo brasileiro: história e imaginário. Portuguese Cultural Studies, v. 1, 2007. Disponível em: < https://scholarworks.umass.edu/p/vol1/iss1/3/>. Acesso em: 19 maio 2020.

FANTINATTI, T. A recepção do sertão brasileiro pela cultura italiana: traduções das obras rosiana e euclidiana. In: GUERINI, A.; TORRES, M.-H.; COSTA, W. C. (orgs.) Literatura traduzida e literatura nacional. Rio de Janeiro: 7Letras, 2008.

GOLDEMBERG, D. Valentia. São Paulo: Grua, 2012.

JACQUEMOND, R. Translation and cultural hegemony: the case of French-Arabic translation. In: VENUTI, L. (ed.) Rethinking translation: discourse, subjectivity, ideology. Londres: Routledge, 1992.

LEFEVERE, A. Tradução, reescrita e manipulação da fama literária. Bauru, SP: Edusc, 2007.

LÓPEZ LÓPEZ-GAY, P. O Banqueiro Anarquista, de Fernando Pessoa - Reflexões sobre a autotradução. Lisboa: Instituto Camões, 2006.

LOWE, E. Jorge Amado and the internationalization of Brazilian literature. Cadernos de Tradução. Florianópolis, n. 2, p. 119-140, 2013. Disponível em:

$<$ https://periodicos.ufsc.br/index.php/traducao/article/view/27683>. Acesso em: 19 maio 2020.

LUCENA, S. C. Entre o eu e o outro: a ficcionalização da história na autotradução de Viva o Povo Brasileiro. 2013. 118p. Dissertação - Universidade Federal de Pernambuco, Recife.

. Identidade/Identidades brasileira: novo romance histórico e a escrita da

resistência em Valentia, de Deborah Goldemberg. Spanish and Portuguese Review v. 4, p. 61-72, 2018. Disponível em: $<$ https://spanportreview.files.wordpress.com/2019/01/7-lucena-1.pdf $>$.

Acesso em: 19 maio 2020.

MELO, C. V. de. Mapping Brazilian literature translated into English. Modern Languages Open. 2017. Disponível em: < https://www.modernlanguagesopen.org/articles/10.3828/mlo.v0i0.124/>. Acesso em: 19 maio 2020.

MORRIS, M. An Invincible Memory By Joao Ubaldo Ribeiro. The New York Times, Nova York, 16 abr. 1989.

Gláuks: Revista de Letras e Artes - jul/dez 2020 - v. 20, n. 2 


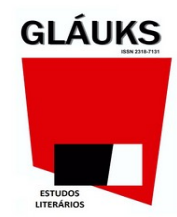

OLIVIERI-GODET, R. Construções identitárias na obra de João Ubaldo Ribeiro. São Paulo: Hucitec; Feira de Santana, BA: UEFS; Rio de Janeiro: Academia Brasileira de Letras, 2009.

. A Translation of An Excerpt from "Viva o Povo Brasileiro" by João Ubaldo Ribeiro. Portuguese Studies v. 3, p. 186-192, 1987. Disponível em: $<$ https://www.jstor.org/stable/i40048493>. Acesso em: 19 maio 2020.

PARKER, J. An Invincible Memory by João Ubaldo Ribeiro. Portuguese Studies v. 6, p. 221224, 1990. Disponível em: < https://www.jstor.org/stable/41104921?seq=1>. Acesso em: 19 maio 2020.

PEREIRA, B. F. Tradução, alteridade e relações de poder em "An Invincible Memory”, de João Ubaldo Ribeiro. 2016. 217p. Dissertação - Universidade Federal da Bahia, Salvador.

RIBEIRO, J. U. Viva o povo brasileiro. 5. ed. Rio de Janeiro: Objetiva, 2009. . An invincible memory. New York: Harper \& Row, 1989. p. 1268 , issue 4529 . . Suffering in translation. The Times Literary Supplement. London, 17 nov. 1989,

TORRES, M.-H. Tradução da cultura: literatura brasileira traduzida em francês. In: GUERINI, A.; TORRES, M.-H.; COSTA, W. C. (orgs.) Literatura traduzida e literatura nacional. Rio de Janeiro: 7Letras, 2008.

TREECE, D. Sinister populism. Third World Quaterly. v. 12, N. 2. 1990. p. 145-7. Disponível em: < http://www.jstor.org/stable/3992265>. Acesso em: 19 maio 2020.

VENUTI, L. A tradução e a formação de identidades culturais. In: SIGNORINI, I. (org.) Língua(gem) e identidade: elementos para uma discussão no campo aplicado. Campinas, SP: Mercado de Letras, 2006.

WERNER, C. O fluxo de traduções do Brasil para o exterior. II Seminário brasileiro livro e história editorial. p. 1-15, 2009. Disponível em:

<http://www.livroehistoriaeditorial.pro.br/ii_pdf/camila_werner.pdf>. Acesso em: 19 maio 2020.

Gláuks: Revista de Letras e Artes - jul/dez 2020 - v. 20, n. 2 


\title{
Us and Them: Reception and Self-Translation in João Ubaldo Ribeiro
}

\begin{abstract}
In the field of Translation Studies, the event of self-translation - which refers to when the authors themselves translate their own work - needs to be explored in contrast to the vast research on translation. Therefore, it must be revisited through investigation since literature from Brazil already brings one exemplary case of self-translation. Hence, in the first part of this article, I discuss the strategies of self-translation in Viva o Povo Brasileiro, translated into English as an An Invincible Memory by its author, João Ubaldo Ribeiro. Secondly, I analyze how the anglophone critic received Ribeiro's self-translation work in comparison to his original novel. Finally, in order to provide a reflection on how Brazilian literature navigates in foreign land, I show that the autonomy of the novel in Portuguese is limited by the rules of a hegemonic book market such as the North American one.
\end{abstract}

Keywords: Literary Translation, Self-translation, Reception; Translation Strategies, João Ubaldo Ribeiro.

Gláuks: Revista de Letras e Artes - jul/dez 2020 - v. 20, n. 2 